\title{
A Study of Radial Forearm Free Flap in Intra Oral Defects following Resection of Oral Cavity Cancers.
}

\author{
Umakanth Goud. B ${ }^{1}$, Manish Gupta ${ }^{2}$, Srikanth.K $\mathrm{K}^{3}$, Mani Kumari.B ${ }^{4}$ \\ ${ }^{I}$ (Surgical Oncology, MNJ Institute of Oncology and Regional Cancer Centre, India) \\ ${ }^{2}$ (Otorhinolaryngology Dept., Govt. ENT Hospital/ Osmania Medical College, India) \\ ${ }_{3}^{3}$ (Plastic Surgery, MNJ Institute of Oncology and Regional Cancer Centre, India) \\ ${ }^{4}$ (Plastic Surgery, MNJ Institute of Oncology and Regional Cancer Centre, India)
}

\begin{abstract}
:
Back ground. Oral Cavity Cancers are most common cancers in our country, India. After undergoing wide excision they all require reconstruction. Radial forearm free flap in one of the reliable free vascularised flap.

Material and methods. In this study we have retrospectively analyzed results of 38 patients who underwent reconstruction by Radial forearm free flap. Patients underwent primary reconstruction following reconstruction.
\end{abstract}

Results: The Total Number of 38 patients underwent reconstruction in which 8 were females and 30 were males. In 27 patients primary site was buccal mucosa, 6 were lip, tongue were 4 and 1 patient had floor of mouth cancer. Overall success rate was ( $89.4 \%$ ). Flap failures were in 4 cases(10.5\%). 2 patients required reexploration due to venous thrombosis. one patient had late graft failure. Donor site healed well in all patients except one where partial loss of skin graft was present.

Conclusion. Its pliable skin, relatively less hair makes RFFF a reliable flap for reconstruction for intra oral Cancers.

Keywords: Radial forearm free flap, graft failure, intra oral defects

\section{Introduction}

Oral Cavity Cancers are common in our Country. It is a serious disease of Public concern. It affects Buccal mucosa tongue and floor of mouth. These Cancers require wide excision resulting in large defects and need reconstruction by Pedicled graft or Vascularised free flaps. Vascularised free flaps with good blood supply provide reliable source for reconstruction. Radial forearm free flap. First described by Young et al [1] in 1981. It's pliability and relatively less hair makes it preferred flap ${ }^{[2]}$ by inclusion of Palmaris longus tendon and part of radius bone this flap can be used to reconstruct composite defects. The lateral antecubital cutaneous nerve could be raised with in the flap, to provide sensory innervation ${ }^{[3,4,5]}$ This thin flap is particularly suitable when pliable soft tissue is required to repair a contour deformity, partial tongue, and soft tissue loss.

\section{Objective}

In this article we want to emphasise on reliability of Radial forearm free flap (RFFF) in reconstruction of intra Oral defects after wide excision of cancers.

\section{Material And Methods}

From June 2011 to June 2016, 38 Patients underwent intra Oral reconstruction after radical Surgeries for Oral Cancers in our institute mnj institute of oncology and regional cancer center Hyderabad. The Medical records were reviewed for age, Gender, Location of Primary tumor site. In immediate Post OP Period Minor and Major complications including graft failures were analyzed.

All patients underwent immediate reconstruction after tumor excision Fasciocutaneans flap was raised with its vascular pedicle having radial artery, cephalic ven and circumflex vein. After inserting the flap at recepient site, $a$ end to end and end to side vascular anatamosis performed. The Recepient artery were facial artery and super or thyroid artery. Recipient veins were external jugular view, Internal jugular veins and facial vein.

Post Operatively close monitoring was done by assessment of temperature, color, and capillary refill. Pin prick test performed when vascular compromise was suspected as suggested by temp, and color changes. If the changes suggested vascular compromise patients were taken to Operation theater for re exportation. (Patients were also analysed for Major \& Minor complications. Minor complications like Hematoma, dehiscence, infection and fistulisation and major like graft failure were analysed. Donor site was resurfaced with split thickness skin graft. 


\section{Surgical Anatomy}

The territory of this flap may extend from the wrist flexion crease to the lower third of the arm. The flap is based on the radial vessel, which courses through the anterior lateral intermuscular septum, with drainage from the venae comitantes or superficial vein such as the cephalic. The skin is supported by small multiple perforators through the fascial septum. The radial artery courses deeply between the pronator teres muscle and the brachioradialis muscle in the upper forearm and between the brachioradialis muscle and the flexor carpus radialis in the lower forearm. Distally, it contributes to the deep palmar arch passing through the anatomic "snuff box" between the tendons of the abductor pollicislongus and extensor pollicisbrevis muscles. A rich vascular network is derived from the radial artery in the forearm. The venous drainage is based on superficial and deep veins. The deep system is composed by the venae comitantes accompanying the radial artery and has an average diameter of $1.3 \mathrm{~mm}$. When possible, the superficial system should be included in the flap (the cephalic and thebasilic veins). The cephalic vein arises from the radial border of the forearm and receives tributaries from both sides of the forearm. It is our preferred vein in transferring this flap. The basilic vein ascends along the ulnar border of the forearm and then travels forward toward the medial bicipital groove where it joins the cephalic vein.

\section{Technique Of Dissection}

Patency of the ulnar and radial arteries should be assessed preoperatively via an Allen test. If delay or poor perfusion through the ulnar artery is noted, the radial forearm flap should not be used. The size of the defect to be reconstructed, three dimensional architecture in complex defects, and the recipient vessels should be evaluated. A tourniquet is placed on the upper arm once the limb is exsanguinated. Skin markings are then performed on the dorsovolar aspect of the forearm. This allows harvest of the cephalic vein during dissection. The flap should be designed as distal as possible in the forearm, but no further than the wrist flexion crease. This allows for the incorporation of as many perforators from the radial artery as possible to perfuse the skin and fascia. The flexor tendons, radial artery and venae comitantes, cephalic vein, brachioradialis muscle, and median nerve are all noted, and the distal vascular pedicle (radial artery and venaecomitantes) is ligated. Elevation can now begin on either radial or ulnar side of the forearm. The plane of dissection is below the antebrachial fascia and above the flexor tendons. To allow skin grafting of the donor site, the paratenon should not be removed. Care is taken not to damage the fasciocutaneous branches emerging from the intermuscular septum. The superficial branches (usually three) of the radial sensory nerve are identified and preserved. The cephalic and basilicvein is divided distally when located within the skin paddle.

The dissection proceeds from distal to proximal to the bifurcation of the brachial artery. This can be done with acurvilinear or inverted V pattern, if there is skin laxity. The inverted V pattern allows split- or fullthickness skin harvesting or grafting the forearm donor area. The dissection should take about one hour. After this time the tourniquet is released, vascularity of the hand is assessed and meticulous hemostasis achieved. Attention is then directed to the recipient vessel. The vascular pedicle is ligated and divided, the flap is transferred to the reconstruction area and partially inset using 3-0 Vicryl sutures. It is critical to conform the radial forearm flap to the defect, including the creation of a sulcus for food movement. Frequently, additional procedures are necessary in 6 months to revise and reshape the flap. The blood flow in the vessels is then assessed using a transonic Doppler. The inset of the flap is then completed and the head and neck area drained. The head and neck defect is closed primarily with interrupted 2-0, and 3-0 Vicryl sutures and staples if enough skin laxity is present. Split- or full-thickness skin grafts are placed on the distal donor defect, and the forearm is dressed in a volar splint for 5 days to provide stabilization until neovascularization of the skin graft occurs.

\section{Results}

Total Number of 38 patients underwent reconstruction in which 8 were females and 30 were males. Mean age was (39.9 yrs) youngest patient was $23 \mathrm{yr}$ and oldest is 66yrs.(Range 23yrs to 66yrs). In 27 patients primary site was buccalmucosa (71.05\%), 6 were lip(15.7\%), tongue(10.5\%) were 4 and 1 patient had floor of mouth cancer(2.6\%) Immediate Post operative Period major Complications like graft failure was in $4(10.5 \%)$ cases. Both were because of venous thrmbosis. One patient developed late graft failure. Eight patients developed minor complications(21.05\%). Hematoma in 2 cases dehiscence in 3 cases infections in 2 and partial necrosis in 2 cases. Over al success rate was $89.4 \%$. Average hospital stay in was 14 days due complications hospital stay was postages by 8 days .Donor site healed wel in all cases except one where partial graft loss was there. Later it healed with secondary intention.

\section{Discussion}

Radial for arm flap is reliable method for reconstruction of intra oral reconstruction for oral cavity cancer after resection. Radial forearm free flap is relatively easy to raise and has good success rates. RFFF has pliable skin paddle, relatively hairless with less bulk spreads over shapes of Oral cattily, easily. ${ }^{(3-8)}$ More bulky 
flaps especially after tongue resection, limit tongue movements and inhibit hypertrophy of muscles. RFFF offer less résistance to movements of tongue ${ }^{(8)}$ RFFF provides vascular pedicle with adequate length. Relatively long vascular pedicle allows Micro vascular anastamoses to be performed away from defect. It is important to avoid irradiated vessels for anastamoses incase of patients who were irradiated preoperatively. ${ }^{(4)}$ t). Over the last few decades success rates of RFFF have greatly improved ${ }^{(9-12) .}$ The Most common cause of graft failure is venous thrombosis. ${ }^{(11-15)}$ The venous system is low flow system and more prone for stasis. Veins can be Compressed by hematoma, poor positioning of vascular pedicle and movements of neck. The arterial flow is rapid wall is thick and problem with thrombosis present at earlier stage then venias problems. Post Operative arterial thromboses is associated with technical difficulties such as size mismatch, calcified vessels and technical mistakes ${ }^{(13)}$. Adequate pedicle length and proper placement is essential to prevent venous thromboses.

Donor site morbidity is due to partial loss of skin graft lose of skin over tendons can cause exposure of tendons adhesions and delayed healing. Associated bone graft as part of composite graft can increase risk of stiff hand due to immobilization. Fascio cutaneous flap without bone requires immobilization for 1 week has less incidence of stiff hand.

In our study mean age was 39.9 yrs (rage 23 to 66yrs). 8 patients were females. 30 patents were males. Jeftery D, sul et al ${ }^{(4)}$ kenth E. Black et al ${ }^{(5)}$ and Bree H. Hauphery et al ${ }^{(6)}$ reported greater portion were older age group in their study. In our study buccal mucosawas common primary site. Revient $\mathrm{S}$ et al ${ }^{(7)}$ and Markeren et al ${ }^{8)}$ had cancer of tongue and floor of mouth malignances as common sites.

In our study Donor site morbidity was significantly less .Only one patient developed partial loss of skin graft loss. The reports in literature showed 2 to $53 \%$ of skin graft failure $0 \%$ to $33 \%$ tendonemposure. Sandeep gupta et al in their study graft failure at donor site was $13 \%$ and healing occurred without further skin grafting in all cause except one.

In our study $4(10.5 \%)$ cases had graft failure and 2 cases were re explored. Both re explored patients had venous thrombosis and subsequently we have lost those grafts. One patient had a delayed graft failure. Sundeep gupta et $\mathrm{al}^{(9)}$ in their studyreported 3/30(10\%) graft failure and minor complications $20 \%(6 / 30)$. Success orate of $90 \%$. Ranjan G. Ayer el al ${ }^{(10)}$ reported 2/17(11.7\%) graft failure, 29\%(5/17) minor complications. Jelena V. Jeremic el $\mathrm{al}^{(11)}$ reported 2/21( $\left.9.5 \%\right)$ graft failure success rate was $(90.5 \%)$.

\section{Conclusion}

Radial forearm free flap is a Versatile flap for reconstruction of intra Oral defects. Because of its pliable skin, relatively less hair. It spreds out easily fits in to intra oral defect with good cosmetic and functional results. The good meticulous technique of raising flap, good vascular anastamosess in required to achieve good results. Our study reveled radial frearm free flap to be reliable method of intra oral reconstruction.

Figures \& Tables:

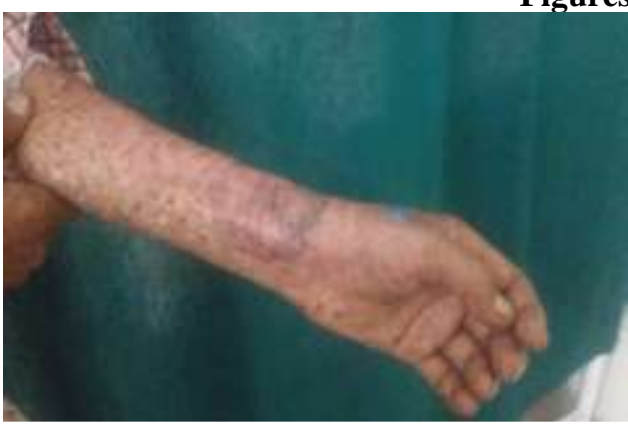

Fig:1. Healed Donar site

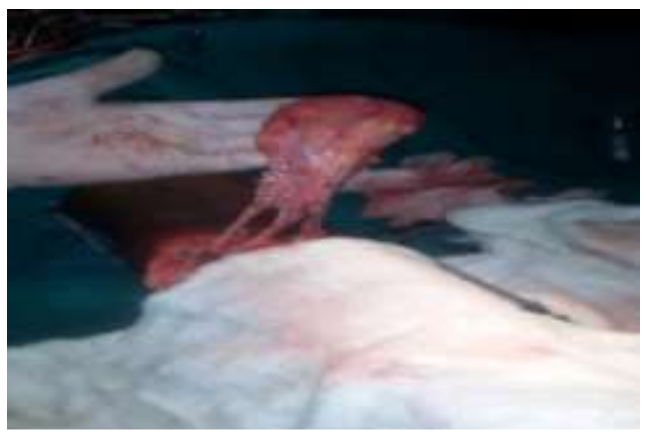

Fig:3. Graft Harvest

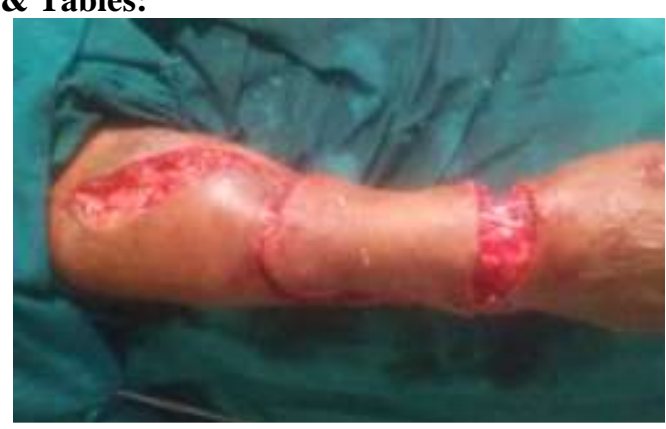

Fig: 2. Incision marking for radial free forearm flap

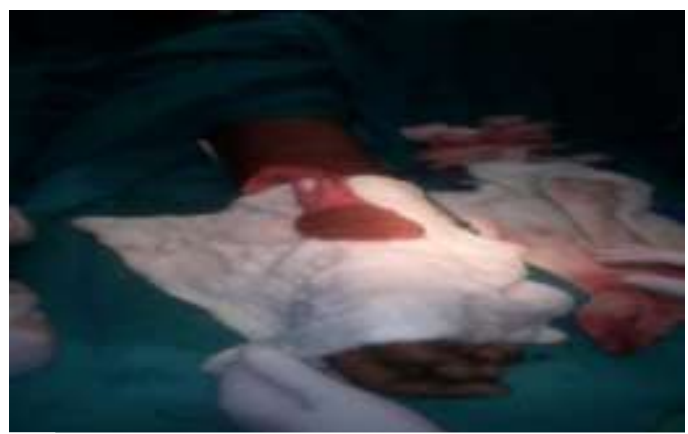

Fig:4. Graft Harvest 


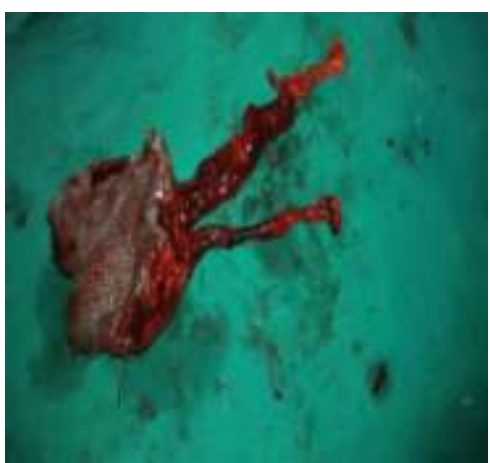

Fig:5. Graft failure due to venous congestion



Fig:5. Post O.P. Photo

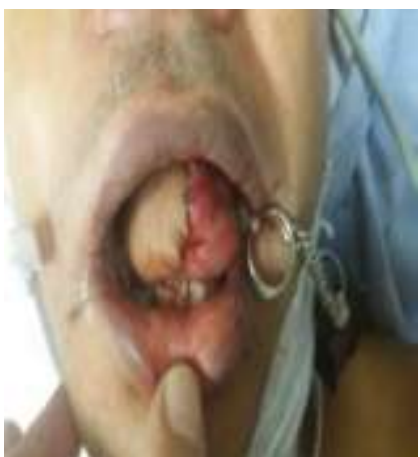

Fig:5. Reconstruction of tongue

Table - I

\begin{tabular}{|l|l|l|l|}
\hline Age & MEAN & $39.9 \mathrm{yr}$ & \\
\hline & Range & $23 \mathrm{yr}$ to 66yrs & \\
\hline Gender & Male & 30 & $(78.9 \%)$ \\
\hline & Female & 8 & $(21.05 \%)$ \\
\hline
\end{tabular}

Table - I Tumor site

\begin{tabular}{|l|l|}
\hline Buccal Mucosa & $27(71.05 \%)$ \\
\hline Lip & $6(15.7 \%)$ \\
\hline Tongue & \\
\hline
\end{tabular}

Table - II

\begin{tabular}{|lc|}
\hline Tumor Site & \\
\hline Buccal Mucosa & $27(71.05 \%)$ \\
\hline Lip & $6(15.7 \%)$ \\
\hline Tongue & $4(10.5 \%)$ \\
\hline Floor of mouth & $1(2.6 \%)$ \\
\hline
\end{tabular}

Table - III

\begin{tabular}{|l|l|l|l|l|}
\hline Complications & minor & & major & \\
\hline & Hematoma & 2 & Graft failure(10.5\%) & 4 \\
\hline & Deliscence & 3 & reexporations & 2 \\
\hline & Infection & 2 & Late graft failure & 1 \\
\hline & Paralicalnecroses & 2 & & \\
\hline
\end{tabular}

References

[1]. Young GF, Chen PJ, Gao YZ, Liu XY, Li J, Jung SH. Forearm skin flaptransplantation: a report of 56 cases. J Plast Surg. 1997; 50:162-5.

[2]. Soutar DS, McGregor IA. The radial forearm flap in intraoralreconstruction: the experience of 60 consecutive cases. PlastReconstr Surg. 1986; 78:1-8.

[3]. Chen CM, Lin GT, Fu YC, Shieh TY, Huang IY, Shen YS, et al.Complications of free radia forearm flap transfers for head and neckreconstruction. Oral Surg Oral Med Pathol Oral RadiolEndod.2005 99:671-6.

[4]. NikolićŽ, Jeremić J, Milosavljević R. Primenaslobodnihmikrovaskularnihrežnjeva u zbrinjavanjudefekataglave i vrata.Vojnosanit Pregl. 2006; 63(8):703-12.

[5]. Jeremić J, NikolićŽ, Drčić L, Petrović A, Jeremić K, Todorović V.Upotrebaslobodnogradijalnogrežnja u pokrivanjudefekataglaveivrata. Vojnosanit Pregl. 2009; 66(4):290-4.

[6]. Hurvitz KA, Kobayashi M, Evans GR. Current options in head andneck reconstruction. PlastReconstr Surg. 2006; 118:122-33.

[7]. Rhemrev R, Rakhorst HA, Zuidam JM, Mureau MA, Hovius SE,Hofer SO. Long-term functional outcome and satisfaction afterradial forearm free flap reconstructions of intraoral malignancyresections. J PlastReconstrAesthet Surg. 2007; 60:5885-92.

[8]. Markknnen-leppannen.M.suominenE.Lethtonen .H. Asko-seijavaraS. Freeflap reconstructions in the management oforal and pharyngeal cancers aaActa otolaryngol.2001 Aprl 121(3) 425-9.

[9]. Guptasandeep,JainDevendra ,Jhala J.T. SaraiyaH.\&Kothariparag . Jayesh D. patel. F Free radial artery forearm flap I reconstruction of oral cavity cancers Our experience.Int J Res Med $2014 ; 3(4) ; 85$ 89.

[10]. Ranjan G ayer ,Rahul gupta .Viragdamania .Mittal shah ,Abisheksharma reconstruction of oral neoplasms in indian set up ; Redebating the utility of Radial forearm free flaps.http;//www.Waent.org/archieves/2010/vol3 -1/20100421 - free-flap- flap.Htm.

[11]. Versatility of Radial Forearm Free Flap forIntraoral Reconstruction Jelena V. Jeremić1,2, Živorad S. Nikolić3 SRP ARCH CELOK.2015 MAY JUNE 143(5-6)256_260. 